\title{
Statistics in the World around Us - A Group Project for an Introductory Statistics Course
}

\author{
Eric Ruggieri \\ Department of Mathematics and Computer Science, College of the Holy Cross, United States
}

Copyright $\subseteq 2019$ by authors, all rights reserved. Authors agree that this article remains permanently open access under the terms of the Creative Commons Attribution License 4.0 International License

\begin{abstract}
This paper describes a group project created for an introductory statistics course. The main idea of the project is to have groups of 2-3 students select a published journal article on a topic of their choice and then present the results of that article to their classmates. The focus of the presentation and subsequent written summary is on the entirety of the statistical process, from formulating a question to drawing the appropriate conclusions from the statistical analysis. Through this process, students interact with many effective teaching techniques including using real data, incorporating active learning, emphasizing conceptual understanding rather than memorization, honing communication skills (both written and oral), learning to work as part of a team, and providing constant feedback. The overall goals of the project are not only for students to become more effective communicators of statistics, but also for them to see how statistics can be used outside of the classroom.
\end{abstract}

Keywords Active Learning, Group Project, Writing, Oral Presentation, Communicating Statistics

\section{Introduction}

Did you ever take a class where you did not see the point? You find yourself asking, 'when am I ever going to use this?' As mathematics and statistics educators, we obviously know the importance of statistics in our everyday lives, but many of our students miss this connection. In fact, students often enter class with less than positive attitudes about statistics [1] - they tend to believe that statistics is demanding, involves lots of math, and is irrelevant to their career goals [2]. So when asked to create and teach an introductory statistics course geared towards our pre-med and pre-health students, one goal was for these students to see how statistics is being used outside of the classroom. Additionally, since speaking and writing are such important parts of effective communication, a second goal was to have these students learn how to communicate the language of statistics.

If you flip on the nightly news, you almost cannot avoid hearing about a recent poll that was taken or a medical study that tells us what we should or should not be eating. Therefore, a simple way to guide students to see the relevance of statistics outside of the classroom would be to look at US census data [3] or polling data obtained from an organization such as Gallup [4]. At different parts of the course you can talk about graphing techniques, sampling distributions (margin of error), or testing hypotheses such as 'a majority of Americans believe that...' Alternatively, one could look at experiments conducted by pharmaceutical companies and discuss their results and conclusions. This project takes a different approach.

When the project was first being designed, a colleague in Biology said to me that he wished he had paid more attention in his first statistics class. At the time, he had no idea how important it would be to the work he was currently doing, gathering data on the body's response to exercise. If we are going to reach our students, then we have to make them see why this material is going to be important to them in the future. This is especially true now that the MCAT exam is placing a greater emphasis on statistical reasoning. From the FAQ section:

"Among the research methods and statistics concepts applicants need to demonstrate are basic probability, measures of central tendency, measures of variability, confidence intervals, statistical significance levels, graphical presentation of data, hypothesis formulation, independent and dependent variables, hypothesis testing, and reporting research results.[5]"

The section goes on to say that, many of these topics are covered in the existing required coursework. However, each of these topics (and more) is also covered in the standard introductory statistics course, so while there may not be a formal statistics requirement on the MCAT, an influx of students wanting to take statistics is entirely possible.

The following describes a group project designed to 
show students in an introductory class how statistics is relevant to their chosen field of study, and also teach them how to be effective communicators of statistics. The project involves reading, presenting, and then writing about a published research paper. This project differs from a more traditional data analysis project in that each group choses their own topic (so every project is different) and since the chosen articles generally go above and beyond what has been covered in class, each group has to do additional background research in order to present their paper. In other words, each group will be presenting on a unique topic, describing the statistical methods used throughout the paper. While the project was originally assigned to a group of science majors, it can easily be adapted to a more general audience.

\section{Background: How Group Projects Improve Student Learning}

There is a vast body of research describing the impact of group projects on student learning. In fact, Dierker et al. [6] states that 'project-based learning in many contexts is more effective in promoting deep thinking, the ability to apply knowledge, communication and reasoning skills when compared to traditional didactic approaches', while Forster and MacGillivray [7] note the 'universal acceptance in the value of having statistics students engage in experiential learning in real contexts, with real data'. Chance [8] describes projects as 'the most valuable learning experience for my introductory students'.

The skills learned while completing these projects encompass both The Guidelines for Assessment and Instruction in Statistics Education (GAISE) approved by the American Statistical Association (ASA) [9] together with opportunities for project-based work. Some of the benefits include: using real data, incorporating active learning, emphasizing conceptual understanding rather than memorization, honing communication skills (both written and oral), learning to work as part of a team, and providing constant feedback to students.

Using Real Data: The use of real data has been advocated for some time, as interesting, real-world problems motivate student learning [10] and can also help improve a student's attitude towards statistics [11] by making the material relevant to a student's particular area of interest [12]. Moreover, real-world data sets are an immediate application of what has been learned in class [13] that demonstrate the 'power, elegance, and even beauty of statistical reasoning', and can persuade students that they are learning critical thinking skills that can be readily applied to almost any career [14]. As an added bonus, students often learn something interesting about the world and gain a sense of pride in actually being able to 'do' statistics [15].

Active Learning: Learning is more complex than merely remembering what you have been told. True learning comes from students having to solve problems for themselves; students learn more from working on open-ended problems than on problems where there is a single correct answer [16]. The project described in this paper is open-ended because each article generally utilizes more than one statistical method in their data analysis, some of which we will not have covered in class. Thus, students are free to choose which method to present, generally have to do some background research on their chosen method, and have total freedom in how they choose to present their statistical method. Small group, project-based activities allow students to become more involved in their own learning since these students must construct knowledge as they learn new material, act as a community of learners, and actively work together to understand statistics [17]. In this setting, students will end up teaching each other, especially when one student understands the material better or learns more quickly than the others. The student who takes on the 'teaching' role often sees an increase in their own level of understanding of the material, a result supported by research suggesting that having individual students teach each other is an extremely effective way to increase student learning [17]. In essence, the goal of each group is to teach their classmates about one of the statistical methods used in their article.

Conceptual Understanding: Many statistics courses are shifting focus to emphasize conceptual understanding of statistical topics over memorization of arbitrary facts and procedures [18]. Radke-Sharpe [19] argues that the interpretation of the analysis and communication of statistical results are just as important as teaching the mathematical equations and theories. Asking a student to apply what they have learned internalizes and conceptualizes the material as opposed to rote memorization of definitions and equations that can be done without an understanding of the underlying concepts. Whereas an exam emphasizes the final numerical answer over the statistical reasoning process, asking a student to read a research article, discuss the statistical methods being used, and interpret the findings evaluates a student's ability to communicate and justify statistical results. Here, a student has to understand why a statistical method is valid as well as how to apply it to the data. Thus, unstructured projects can be viewed as essential for students to achieve a working understanding of statistics [20].

Communication Skills: The ability to communicate statistical findings, both orally and in writing, is an important part of any statistical analysis [7]. Samsa and Oddone [21] point out that many people's first encounter with a statistician is through the written word, and many researchers have acknowledged that a good statistician must also be good at communicating their results in a form understandable to one's colleagues [22]. The process of writing about a subject can clarify and reinforce 
understanding. Writing makes one think more carefully about the structure and organization of an argument, allowing students to 'better function in today's society as effective problem solvers, communicators, and critical thinkers' [19]. Additionally, a project that incorporates writing allows students to improve and practice a skill that will be heavily used in any technical field later in life. In short, writing activities appear to be helping students learn [16].

Small group activities also provide students with opportunities to verbally express their understanding of what they have learned, as opposed to only passively interacting with the course material [17]. In fact, some of students' most significant learning gains come from debating ideas with each other [18]. Explaining a solution to someone else helps synthesize and solidify the information in your own mind, and also gives repetitive practice with the language of statistics [18]. A person who does not understand the material will not be able to effectively communicate it to someone else [22].

Teamwork: The ability to work as a team is becoming an increasingly important skill for the modern worker; collaboration is viewed as essential to solving many of the problems faced today [6]. Since the sharing of work and talents is seen by business leaders as necessary characteristics of successful companies, businesses are increasingly looking for employees who are able to work collaboratively on projects and to solve problems as a team $[17,20]$. Small group work not only helps to build collaborative problem-solving skills and camaraderie [14], but encourages debate and discussion among group members [18], allowing students to learn from one another by comparing and explaining different (equally valid) solutions [17]. This helps students learn to respect other viewpoints, other approaches to solving a problem, and other learning styles [17]. Thus, having students work together in small groups has not only been shown to be a valuable learning experience [13, 14 and references therein], but also valuable experience for the modern work environment $[7,18]$.

Assessment: In order to capture the full spectrum of student learning, formal assessment should not be limited to traditional tests and quizzes [16]. Thus, projects represent an 'authentic' assessment technique in that they obtain information about a student's understanding of and ability to apply statistical concepts to real life situations [18]. By incorporating both a written and oral component of the group project, students have multiple avenues with which to display their familiarity and comfort with statistical concepts. Though time consuming, constant communication between student and teacher on a multi-part project is extremely important as it provides multiple opportunities for students to express their ideas and receive feedback, which enhances learning $[13,16]$. Ideally, the continuous feedback will help the students to regard the project as a semester-long learning experience instead of just focusing on the final grade [13].

\section{Context}

The pilot version of this group project was assigned at Duquesne University, which has just over 10,000 students in 11 different schools of study, over half of which are undergraduates. As a part of the university's core curriculum, all students are required to take one mathematics course, and depending on their major, many are required to take a statistics course. Each semester the Department of Mathematics and Computer Science offers approximately 7 sections of 'Introduction to Biostatistics', with each section capped at 30 students. A majority of these students were sophomores who primarily come from the School of Health Sciences (physical therapy, occupational therapy, etc.), the School of Pharmacy, and the School of Life and Environmental Science. The course could also be taken as an elective by mathematics and computer science majors.

More recently, the project has been assigned at the College of the Holy Cross, a small liberal arts college of roughly 3000 students. Each semester, the Department of Mathematics and Computer Science offers 4 sections of 'Statistics', which is a non-calculus based introductory statistics course capped at 24 students. This particular course was new to the college and was developed with input from departmental colleagues in response to the new MCAT requirements. Each pre-med and pre-health science student has been advised to take this course at some point after their freshman year. However, the course also contains students from across the College, as it is the first course in our minor program in statistics. From these two settings, one can see that the project is applicable to a broad range of circumstances at different colleges and universities.

\section{Project Description - Presenting a Research Paper}

The goal of this project is to be able to read, understand, and then discuss statistics as it applies to a real life situation. Specifically, the learning outcomes are stated as (see Appendix A):

1) To appreciate how the concepts we are learning in class can be applied to your individual fields of study.

2) To become more comfortable reading and thinking critically about a published journal article.

3) To comment on the underlying assumptions and statistical methodology used in a journal article.

4) To give you an opportunity to hone your presentation skills and receive feedback.

5) To practice the art of technical writing.

Students work in teams to present the results of a 
research article to their classmates, paying particular attention to: (i) the motivation for the project; (ii) the method of data collection; (iii) the statistical methods that were used to analyze the data; and (iv) the main results and conclusions drawn by the authors.

Group projects are chosen rather than individual projects for two main reasons. The first is time - both class time and instructor time. Each section of the course is generally filled to capacity at 24 students. As it is, having groups of students give 5-10 minute presentations during class takes up nearly a week of class time; allowing all 24 students time to make individual presentations would take too much time away from the course material. Besides class time, an instructor might also be concerned with the amount of time it takes to assess and provide feedback on these projects. When a TA is present, the temptation may exist to try and pass off some of the grading. However, as Ledolter [20] notes, TA's will often lack the experience to grade open-ended projects that do not have a 'correct' answer. This means that the instructor has to be fully responsible for assessment. In total, each project takes 60-90 minutes of instructor time across the semester. So while 24 projects can be overwhelming, forming groups of size 2-3 makes the grading of 8-12 projects much more manageable.

A second reason for having the students work in groups is the potential difficulty of the statistical analysis in the chosen article. These students have taken just a single semester of statistics, so their statistical knowledge is limited to constructing simple confidence intervals and performing basic hypothesis tests. Many of the papers chosen by students include more advanced statistical techniques than we are able to cover in a single semester, meaning that the students will have to do a little background research before being able to present their paper. Moreover, parsing through the information presented in the paper can also pose a challenge. Thus, allowing students to work together on these tasks helps to alleviate some of the potential problems by drawing on the collective insight of the group.

The syllabus states:

Group Project: Since the goal of this course is to understand how statistics are used in a real-world setting, you will be asked to find a research paper that uses statistics and present the results of this paper to your classmates. The paper you wish to present and a short (1 page) description of the statistical methods used in that paper will be due $\mathbf{x x x}$ (worth $10 \%$ of the project grade). The second part of this project is a brief meeting (by $\mathbf{x x x}$ ) in order to go over the statistics discussed in your journal article $(10 \%)$. The final $80 \%$ of the project grade will be evenly split between your presentation and a written report. No one is expected to be an expert on the topic that you have selected. Therefore, both the presentation and written report/summary of your research paper should introduce the problem you are investigating, describe the methodology for gathering and analyzing the data, and contain a summary of the results. Try to think critically about any conclusions drawn in the paper. Are they adequately supported? While the focus of many published journal articles is on the underlying biology, your report should be more focused on how the data was gathered and the statistical methods used, as well as an introduction to the biological question being studied. The project presentations will take place on the final 2-3 days of class; the written reports (3-5 pages) will also be due at that time and should mirror your presentation. Late submission of any of the three pieces of this project will not receive full credit. Additional project details and example papers will be forthcoming."

[due dates omitted]. Each part of the project will now be described in greater detail.

\section{Selecting a Topic - 10\% of Project Grade}

In the second half of the semester, the group projects are reintroduced to the class and roughly 20 minutes of one class period are spent discussing the various ways to choose a topic. Detailed instructions/directions for how to complete the project are handed out and posted on the course website (see Appendix A). The project description includes information on all three parts of the project, including how to select a topic and what types of papers are appropriate, setting up a meeting to discuss the paper, and the main ideas that should be included in both the presentation and written report. Students are allowed to choose their own groups, since many of them have multiple classes with the same people, and then those who are left are either paired up or added to existing groups. Additionally, each group is allowed to choose their own topic. Ideally, this increases student interest and their motivation to actively participate in the learning process, as they can better see the relevance of statistics to their major. To date, there have not been any major issues related to group dynamics.

Perhaps the most useful resource for science articles is PubMed [23], as this site provides a vast array of full text articles. Students are advised to search for key words such as 'confidence intervals', 'p-values', or 'odds ratios' along with a topic that they are interested in such as 'sports', 'music', or 'cancer'. For example, searching for 'confidence interval sports' returns over 600 full text articles to choose as project topics. A brief reading of the abstracts can help to quickly identify appropriate papers, and it takes no more than a few minutes to identify several potential papers that are suitable for presentation. Other options for finding journal articles include searching Google Scholar [24] or a specific journal's website. Sample papers that were presented in previous semesters are also posted on the course website, but with so many options available to them, the students are discouraged from selecting these topics again. Papers that have been presented include: 
- Game-related statistics that discriminated winning, drawing, and losing teams from the Spanish soccer league [25]

- $\quad$ Lung Function in Rescue Workers at the World Trade Center after 7 Years [26]

- Consumption of sweet foods and breast cancer risk: a case-control study of women on Long Island, New York [27]

- Do Motion Controllers Make Action Video Games Less Sedentary? A Randomized Experiment [28]

- Effect of Smoking Scenes in Films on Immediate Smoking: A Randomized Controlled Study [29]

- Adult sports-related traumatic brain injury in United States trauma centers [30]

- Neuroblastoma, Body Mass Index, and Survival: A Retrospective Analysis [31]

- Metabolic profiles of male meat eaters, fish eaters, vegetarians, and vegans from the EPIC-Oxford cohort [32]

- Public opinion on the affluenza defense, race, and sentencing decisions: results from a statewide poll [33]

The goal is to find applications of statistics rather than statistical theory, so students are advised to avoid papers that are heavily mathematical.

Once each group has chosen their topic, they are asked to turn in a one-page summary along with either a paper or electronic copy of their chosen research article so that the instructor can read it as well. From my perspective, the main goal of the one-page summary is to make sure that they have actually read the paper, although it could also be used as an opportunity to 'approve' or provide feedback on each group's topic. Each paper is read and comments/notes are made that point out the important parts of their paper including the experimental design, the statistical methods being used, and the results generated using these techniques. Identifying the key aspects of the paper can be a bit overwhelming to some students, so the instructor scaffolds to provide a starting point. Providing feedback at this stage takes approximately 30-40 minutes of instructor time per project, but pays huge dividends with respect to the quality of the projects.

\section{Project Meetings / Participation - 10\% of Project Grade:}

The second part of the project is a brief meeting with each of the groups. The project meetings take place approximately one week before the start of the presentations and serve as an opportunity for the instructor to 'check in' with each of the groups. At this point, each group has had time to reflect on the comments that were made on their article and begun to think about how they want to give their presentation.

Each group is asked to present one of the statistical methods used in their paper (generally, there are several to choose from). Thus, there are two types of papers - those that use statistical methods that we have covered in class, and those that do not. In either case, evaluation is based the clarity of the explanation, so there is no incentive to choose one type of paper over the other. Given the limited statistical knowledge accrued by the end of a single semester, papers that use more advanced statistical techniques can often be intimidating to the students, but in my experience, they can end up being some of the best presentations.

If a group chooses to present a statistical method that we have covered in class, then they should treat their paper like a giant word problem and try to reproduce one of the results given in the paper. During their presentation, they can walk their classmates through the calculations, pointing out the values they would use for $\bar{x}, \hat{p}, \mathrm{z}$, or $\mathrm{t}$, as appropriate. As easy as this may sound, some papers do not provide enough information (such as missing standard deviations) to fully solve a problem, so each group is asked to get through as much of the calculations as possible and then indicate the information that is missing. Ultimately, the goal is for these students to be able to verbalize how to solve a statistics problem.

On the other hand, if a group chooses to present a statistical method that we have not covered in class, then they are not expected to be able to reproduce the calculations in the paper. Instead, these groups are asked to give a brief overview of the statistical method - why and how it is used - before talking about the results obtained by the authors. Our textbook $[34,35]$ ends up being a good resource for topics such as regression, chi-square tests, ANOVA, and some non-parametric methods, such as the Wilcoxon signed rank test. Obviously, not all topics will be covered in our textbook (such as the Kruskal Wallace test and Kaplan Meier curves), so I have had students borrow textbooks from my bookshelf or use Wikipedia [36] as a starting point. In these situations, some groups have used visual aids, while others have gone through simple examples to give their classmates at least a superficial understanding of the method that was used in their paper.

For the project meeting, each group is asked to bring a brief outline of their presentation with as much of the statistical equations/calculations worked out as possible. Students dread public speaking [14], and since this may be the first time that many of these students will be presenting the results of a research article to their classmates, the main goal is to make sure that each group is comfortable talking about the statistics in their paper. If the group has all of the statistics figured out, then the meetings take less than 5 minutes. On the other hand, if a group has a question about something in their paper, then we can take the time (15-20 minutes) to talk more in depth. This time can prove especially useful to the groups who choose to present a statistical method that we have not covered in class, as it provides an opportunity to further clarify the equations from a textbook [34,35, among others] or a Wikipedia page [36] that they have read. It can also help those groups who cannot seem to find all the information (such as standard 
deviations) needed to build their confidence intervals. Points for this part of the project are based upon a group's preparation for the meeting. Only one group has ever been awarded less than the full 10 points when it was obvious that they had neither tried any of the calculations nor looked up any background information on their topic.

The second half of this participation grade is earned by students giving feedback to each other on their presentations. Students are asked to comment on one item that they enjoyed and one item they thought could be improved about each group's presentation (see Appendix A). The feedback component of the project was initiated for two primary reasons. First, it is helpful for each group to receive feedback from more than just a single source (the teacher), who is somewhat biased because they have seen the students work on their project from start to finish. Second, there was a noticeable drop in attendance on the latter days of presentations - an issue, which has now been eliminated. However, since the use of student feedback coincided with my change in institution, it is unclear whether this increase in attendance is due solely to the implementation of a participation grade.

\section{Project Presentations - 40\% of Project Grade:}

Each project presentation is 5-10 minutes in length and takes place during the last 2-3 days of class each semester. Ideally, the lost lecture minutes are more than offset by the time each student spends outside of class learning statistics and working on their projects. Through these presentations, an instructor learns about a group's ability to summarize the important points of a paper, use statistical terminology in a coherent manner, communicate results, and in general, explain ideas to their classmates [18]. Effective communication requires the students to develop a deeper understanding of the statistical concepts than does solving a homework problem.

Students are given a fairly detailed list of the major points that their presentation should cover, including background to their topic, data collection and experimental design, one statistical method used in the paper, major results and conclusions, and any limitations of the study (see Appendix A for the handouts and scoring rubric associated with this project). Whereas many of the papers focus more on the scientific question than on the statistics, students are instead expected to 'shine light' on the statistical methodologies used by the authors.

The presentations can be in any format, although the vast majority of groups have chosen PowerPoint or Prezi as their presentation medium, primarily to incorporate visual aids into their talk. Other presentation strategies have included handouts, hand-written examples on the whiteboard, and simply speaking from the podium in the room. One group even brought in cupcakes and wore pink $\mathrm{T}$-shirts to talk about a research article related to sweets and the incidence of breast cancer [27]. The presentations give each student in the class an opportunity to 'speak' the language of statistics.

\section{Project Written Reports - 40\% of Project Grade:}

The second major component of the group project is the writing of a final report, which highlights the important points of the research article. Simply writing a summary of someone else's article is not much practice in writing statistics. However, by shifting the focus of the paper to explaining statistical methodology - experimental design, underlying assumptions, and a description of statistical procedures and equations -the students are asked to do something quite different. Writing a short paper forces the students to synthesize the components of the article and communicate them in a clear and concise manner [37], including a correct interpretation of the survey results using ordinary language that can be understood by their classmates. Ideally, the written reports should be 3-5 pages in length and cover the same points as the presentations (see Appendix A). Essentially, each group is writing down what they said out aloud during their presentations. Whereas the goal of the presentations was to 'speak' statistics, here the goal is to be able to 'write' statistics.

Again, a major concern for instructors is the increased workload for both the instructor and students (see for example, [7] and references therein), but while writing in a statistics course may increase the work involved, the benefits far outweigh the sacrifices [22]. In my experience, each report takes approximately 30 minutes to read and provide feedback, making the project well worth the time.

Examples of projects submitted by students can be obtained by contacting the author.

\section{Student Reactions}

Chance [18] notes that for an assessment technique to be effective, students have to understand why it is being used and how it will enhance their learning. Chance [18] also comments that students will 'resent' an activity if they feel the time required is excessive. The student evaluation surveys given at the end of each semester do not specifically ask about the project, but instead ask 'what aspects of the instructor's teaching was most effective?' and 'how can this instructor improve his/her teaching effectiveness?' Initially, this project had some negative feedback, primarily because the students did not see the connection to their other courses. Specific student comments included: 'I do not understand the relevance of the project', 'not a big fan of the end project, it wasn't very helpful', 'the final project feels like busy work', and 'it just seemed like everything was crammed towards the end of the semester'. From these student comments, it is clear that the motivation for the project was lacking.

When the project was assigned again the following year, much more time was spent trying to better motivate its relevance. Now, two approaches are taken. First, students 
are then told that someday in the future (i.e. in a future job) they may be asked to read a technical report or a research article and either talk about or present the findings of that article to their peers. As an example, a small group of Holy Cross alumni who are entrepreneurs were recently featured in a panel discussion on campus in which they were asked about the skills they wanted all graduates to have upon finishing college. These entrepreneurs stated that they wanted students to have more opportunities to speak, write, work in groups, and solve open-ended problems. This project will provide an ideal setting to practice these skills. Second, photocopies of abstracts from various clinical studies are handed out and then discussed with the class. This can be used as an opportunity to point out the statistical terminology used in each abstract, describe its interpretation, and then made a connection to the appropriate topic listed in the course calendar. Moreover, if these abstracts are chosen well, immediate connections can be made to a student's chosen field of study.

Student feedback on the project improved dramatically. In year two, under 'what aspects of the instructor's teaching were most effective?' students commented:

- 'The group project illustrated how the material we were leaning is applicable to real life studies'

- 'The statistics final project was well spaced out so we had enough time to complete it.'

- '[The] outside of class guidance and gave an assignment for a group presentation'

- ' '... the papers which allowed us to apply statistics'

- $\quad$ 'Very helpful on the projects and very understanding of students' mistakes.'

Additionally, under 'how can this instructor improve his/her teaching effectiveness', one student wrote:

- 'maybe the difficulty of the final project. It's challenging, but to counter that, he is going to help me through it, so I can't really complain'

Several students also commented on the value of the feedback they received throughout the semester. Thus, while a substantial time commitment on the part of the instructor, the group project seems to be a valuable learning experience for these students, a conclusion echoed by several others including Chance [8], Fillerbrown [13], Stromberg and Ramanathan [22], and Smith [14], who stated that 'using team projects produced survey information from students suggesting positive student attitudes and an increased sense of relevance for the course'.

Survey data were collected specifically to assess student's learning outcomes. Since skill-based student learning outcomes (see Section 4) cannot be measured on a traditional quiz or test, student attitudes towards the project were instead sought. Students were asked whether or not they agreed with six statements related to the project. A total of 66 students were enrolled in three sections of 'Statistics' when the survey was administered, 63 of whom answered at least one of the supplemental questions.

As shown in Table 1, a vast majority of students agreed that the project was beneficial. In particular, $82 \%$ of students felt that the project enhanced their appreciation of how statistics is used in their field of study, $80 \%$ became more confident in reading and understanding scientific journal articles, and $73 \%$ became more sure of their ability to learn new statistical techniques. The last point is especially positive, as these are students required (rather than choosing) to take an introductory statistics course, many of whom have developed a 'fear' of mathematics. In sum, by the end of the course, students felt confident taking what they learned and applying it to a new situation. In addition, $81 \%$ of students appreciated being assessed in a manner other than a traditional quiz/exam (as is common in STEM classrooms) and 79\% felt that the project was a valuable addition to the course. Thus, a vast majority of students felt that they gained more from the overall project experience than they otherwise would have from one or two additional lectures worth of content. What these students probably don't realize is that it would take several weeks to cover all of the statistical concepts that they were exposed to during 2-3 days of class presentations. Obviously, the student presentations do not cover the topics in the same depth, but the exposure to these ideas and the connections to what was learned in class during the semester are key.

Table 1. Assessment of Student Learning Outcomes

\begin{tabular}{|l|c|c|c|c|c|c|}
\hline \multicolumn{1}{|c|}{ Question } & $\begin{array}{c}\text { Strongly } \\
\text { Disagree }\end{array}$ & $\begin{array}{c}\text { Slightly } \\
\text { Disagree }\end{array}$ & Neutral & $\begin{array}{c}\text { Slightly } \\
\text { Agree }\end{array}$ & $\begin{array}{c}\text { Strongly } \\
\text { Agree }\end{array}$ & $\begin{array}{c}\text { \# of } \\
\text { Responses }\end{array}$ \\
\hline $\begin{array}{l}\text { The project helped me to understand /appreciate how } \\
\text { statistics is useful to my major and/or a future job }\end{array}$ & $0.0 \%$ & $3.2 \%$ & $14.5 \%$ & $41.9 \%$ & $40.3 \%$ & 62 \\
\hline $\begin{array}{l}\text { The project helped me to become more confident in } \\
\text { reading and understanding a journal article }\end{array}$ & $0.0 \%$ & $3.3 \%$ & $16.4 \%$ & $42.6 \%$ & $37.7 \%$ & 61 \\
\hline $\begin{array}{l}\text { The project increased my confidence in my ability to } \\
\text { learn new, more advanced statistical techniques }\end{array}$ & $0.0 \%$ & $0.0 \%$ & $27.4 \%$ & $45.2 \%$ & $27.4 \%$ & 62 \\
\hline I enjoyed the opportunity to work in a group setting & $1.6 \%$ & $11.5 \%$ & $16.4 \%$ & $42.6 \%$ & $27.9 \%$ & 61 \\
\hline $\begin{array}{l}\text { I was glad to be assessed/graded on something other than } \\
\text { just quizzes and tests }\end{array}$ & $1.6 \%$ & $3.2 \%$ & $14.5 \%$ & $19.4 \%$ & $61.3 \%$ & 62 \\
\hline $\begin{array}{l}\text { Overall, I feel that the project was a valuable addition to } \\
\text { the course }\end{array}$ & $0.0 \%$ & $4.8 \%$ & $16.1 \%$ & $29.0 \%$ & $50.0 \%$ & 62 \\
\hline
\end{tabular}


Oddly enough, the question with the most negative feedback was related to working in groups, with approximately $13 \%$ of students stating that they did not enjoy working in groups. Anecdotally, this response is not unusual, as colleagues have commented that they are seeing a similar pattern in their own courses. The Mathematics major at the College of the Holy Cross requires each student to complete a 'project course'. These courses ask students to complete a final project in lieu of a final exam, with students generally given the choice to work individually or in groups. Our department has noticed a trend where an increasing number of students are choosing to work on individual projects. Other than the slightly negative reaction to this one supplemental question on an end-of-semester evaluation form, less than $5 \%$ of students disagreed with any of the other statements. The results were similar across all three sections of the course. IRB approval was obtained to use this data in this manuscript.

\section{Successes and Lessons Learned}

The project described in the previous sections has been quite successful in terms of meeting its stated student learning outcomes, its content coverage, and its perceived value among the students. With respect to student learning outcomes, students have an opportunity to practice their communication skills (both written and oral), work in teams, and take ownership of their learning, all of which align with the GAISE recommendations published by the ASA. In addition, the project assesses student learning in a variety of ways, which gives a more complete picture of what a student actually knows. From a content point of view, there is much more to statistics than what can be covered in a one-semester introductory course. Asking students to research and then talk about a variety of statistical techniques applied to an even greater number of scenarios shows the utility of statistics to each student's chosen field of study. More importantly, students come to realize that they actually know what the 'numbers' mean and how to interpret the results of a statistical analysis in the context of their study. Finally, students seemed to genuinely enjoy and appreciate the project, as evidenced by the response to the supplemental questions in our end of semester course survey.

However, each new assignment also has its share of pitfalls. The first iteration of the project lacked both motivation and direction. The lack of motivation was not immediately evident, but showed up quite prominently in the course evaluation forms. Students failed to make the connection between the articles they were reading/presenting and their other coursework. Thus, a more concerted effort was made in each successive semester to talk about how statistics is being used within other disciplines, starting with the discussion of a clinical trial on the first day of class. Evidence for the lack of direction comes from a pair of students who chose a paper that described a new statistical method rather than an application of an existing technique. The paper was filled with proofs, and while the 'results' section had an application, it felt like an afterthought. Having a pair of math-phobic, students present this type of article would not have gone well for anyone, so the students were asked to make another selection. With more guidance provided by the instructor, these two students were able to select an appropriate paper to present.

Incorporating a student feedback component to the project addressed two issues that arose with its structure during the initial iterations. In particular, attendance dropped during the presentations as students did not always attend class on the days they were not presenting. To combat this, students are now asked to critique their classmates' presentations in order to earn a participation grade. This addition to the project has largely eliminated any attendance-related issues. As an added bonus, each student now receives feedback from a number of sources, which gives a more complete picture of how the presentation came across to people who are unfamiliar with the study. This type of feedback is incredibly valuable and nicely parallels with the experience of giving a workplace presentation in front of colleagues who are not intimately involved with the project. Moreover, this type of feedback is substantively different from what a student would receive from their instructor, a person who has been working with each group on their project for several weeks, and who has a deeper understanding of the statistical methods being used in the study.

A final pitfall to be aware of with this project is time. The structure of the project requires the instructor to have a lot of contact with each group. The more time that an instructor can dedicate to each group, the better each project will become. But that time adds up. Thus, an instructor needs to strike an appropriate balance the amount of time dedicated to this project and their other responsibilities at the College.

\section{Conclusions}

The group project described in this article aligns well with many of the current trends in statistics education including using real data, collaborative learning, and writing [38], as well as the current guidelines for statistics education (GAISE) approved by the ASA [9]. Moreover, it fits with the growing desire for educators to use projects in an introductory statistics course [38]. The project is innovative because it asks students to read about statistics, write about statistics, and speak about statistics in a context directly related to their chosen field of study. Additionally, it is not a 'one size fits all' project where every group analyzes the same data set. Instead, each group works on a 
different topic and gives a unique presentation on a diverse set of statistical methods. The project gauges the students' understanding of the entire statistical process, from the formulation of a question, to data collection, statistical analysis, interpretation, and the drawing of appropriate conclusions. Additionally, students have an opportunity to develop communication and problem solving skills as they work together in groups, essential skills for today's worker.

Students learn statistics by doing statistics and will be more motivated to learn if they can see the relevance of the topic to their lives. Each of these students has an opportunity to see how statistics is being used in their own field of study and why they were being 'forced' to take a statistics course. As an added bonus, they also have the opportunity to read and present the results of a research article in what is meant to be a stress-free setting.

Learning how to effectively communicate an idea both orally and through writing is an important skill for all students to have, as is being able to apply what they have learned in the classroom to solve a real world problem. Thus, the goals of this project are simple: to have students become more effective communicators and to see how the topics that we have covered that semester are being used outside of the classroom. Being able to communicate statistical ideas both orally and in writing are important skills that are sometimes overlooked in a traditional statistics classroom, skills that help to solidify knowledge for a student.

\section{Appendix - Handouts and Scoring Rubric Associated With "Presenting a Research Paper"}

\section{Group Project Description}

Goal: To be able to read, understand, and then discuss Statistics as it applies to a real life situation.

In order to accomplish this goal, I would like each group to:

1) Find a journal article of interest to the members of your group

2) Present your article to the class by describing:

a The motivation for the project

b The data collection and processing methods

c The statistical methods that were used to analyze the data

d The results and conclusions drawn by the authors

3) Submit a 3-5 page written report about your article. Your written report should mirror your presentation.

Some day in the future [i.e. in a future job] you may be asked to read a technical report or a research article and either talk about or present the findings of that article to your peers. As an example, a small group of Holy Cross alumni who are entrepreneurs were recently featured in a panel discussion on campus in which they were asked about the skills they wanted all graduates to have upon finishing college. These entrepreneurs stated that they wanted students to have more opportunities to speak, write, work in groups, and solve open-ended problems. This project will provide an ideal setting to practice these skills.

\section{Specific Learning Outcomes:}

1) Since each of you are 'required' to take a statistics course, this project will help illustrate how the statistics we are learning in class can be applied to your individual fields of study.

2) To become more comfortable reading and thinking critically about a published journal article.

3) Specifically, to comment on the underlying assumptions and statistical methodology used in a journal article. Chances are that we will not have covered the particular method used in your article, but you should now have the statistical foundation necessary to be able to learn about and then interpret a new statistical technique. My goal is to help guide you through this process.

4) To give you an opportunity to hone your presentation skills and receive feedback.

5) To practice the art of technical writing. Yes, it is an art. Yes, it is different from prose. And, yes, it takes a lot of practice to master.

\section{Guidelines for selecting a paper to present [10 points]}

1) Try to find a paper where an experiment has been performed. That way, you can talk about how the data was gathered, treatment versus control groups, and then the results. Observational studies are also possible, as long as there are different treatments to compare.

2) Look for articles that talk about Confidence Intervals and P-values. We have or will cover these topics in class before the end of the semester.

3) We will not be able to cover linear regression, ANOVA, or nonparametric statistics [Fisher Exact Test, Wilcoxon Signed Rank Test, Kruskal-Willis, etc.] this semester. Don't be afraid of these topics! There have been several successful presentations in the past on these topics. If your article includes any of these, you can still use that article, but you will have to research how this method works and briefly present it to the class before discussing your results. You will not be expected to go into as much detail about the calculations in the paper since it is a method we don't cover in class.

4) Avoid articles that are heavily mathematical. If you see a large number of formulas, chances are the paper uses some fairly advanced statistical techniques. Our goal is to find applications of statistics rather than statistical theory. 
After you have selected your article, please email me an electronic copy of the paper or turn in a paper copy along with a one-page summary of the article.

\section{How to find an article?}

- Search PubMed [www.ncbi.nlm.nih.gov/pubmed/]. Enter the keywords confidence interval, p-value, student $\mathrm{t}$ test, relative risk, odds ratios, etc. - See our Moodle site for a link to PubMed and further instructions on searching for a topic.

- Search Google Scholar for some of the same keywords

- Look through specific journals

- Journal Suggestions:

1) New England Journal of Medicine

2) Nutrition Journal

3) Journal of Sports Science and Medicine

4) Journal of Pharmacology and Experimental Therapeutics

\section{Meeting to Discuss the Paper [part of 10 point participation grade]}

In lieu of a formal rough draft, I would like each group to stop by my office sometime on or before [date] so that we can discuss the statistical methods in your paper that you are planning to present to the class. Please bring a brief outline of your presentation with as much of the statistical equations/calculations figured out as possible. Points are earned based on your preparation for this meeting [rather than on how accurately you have covered each section of the paper]. If you have the calculations figured out, this meeting should take less than 5 minutes. If not, this is a time for you to ask questions and for me to help guide you in the right direction. We are having this meeting by the [date] because presentations could potentially begin on [date] (depending on the number of groups). More likely, the presentations will begin on [date]. Ideally, all of the group members should be present.

\section{Presentation $[40$ points]}

During the last two days of class, you will give a presentation to the class on the journal article that you have selected. The presentation should be 5-10 minutes in length [any format] and try to cover the items below. When presenting, keep in mind that none of the rest of us have read your paper, so try to explain any 'big words' or abbreviations used by the authors. [For example, don't say 'the FEV level in the patients was...' without telling us what FEV stands for or say 'Egg mimicry' without explaining the term]

1) Give the background to the issue being studied.

a. Ex. If your paper deals with HIV transmission, give some statistics and background about HIV.
2) Is this an Experiment or an Observational Study?

b. Experiment - Explain the new treatment being tested

c. Observational-Describe the treatment and control groups

3) Describe how the subjects were 'collected' and assigned to each of the treatment groups

d. Ex. Randomization? Double-blind? How many?

e. Were there any issues with subjects during the experiment? [ex. dropouts]

4) Discuss the main results.

f. Describe to the class how the statistics they used were calculated. There are two cases:

i. If this is a method that we have talked about in class, show us the equations and try to duplicate their results by filling in the numbers.

ii. If this is a method that we have not talked about in class, give a brief description of how the method works and try to come up with a simple example that all of us can understand. Then present the results in the paper (In this case, there is no need to try and duplicate their calculations)

g. Give the conclusions associated with your calculations

5) Are there any limitations/ lurking variables/major issues you have with how the study was conducted?

6) Anything else that you find interesting in the article!

\section{Feedback from Classmates [part of 10 point participation grade]}

A learning experience is always more valuable if you can get feedback on your work. Thus, I am going to ask each of you to briefly comment on your classmates' presentations. Specifically, I would like each of you to comment on one positive aspect of the presentation (something you found interesting about the project, a clear explanation of some idea, etc.), and one area where you thought the presentation could be improved (more background on some part of the study, an unclear explanation of a statistical idea, general comments on public speaking, etc.). I will pass out forms for you to fill out on the day of the presentations. Your classmates' comments on your project will be anonymous and will not in any way impact your grade on the project.

Earlier I mentioned how you might be asked to present the findings of a technical report or research article to your peers at a future job. Think of your classmates as your peers at work. How did your presentation come across to someone who has no prior knowledge about your topic? My feedback will be slightly biased because I have been working with you throughout this process. The idea is for you to get feedback from more than just a single source. 


\section{Final Report [40 points]}

On the last day of class, please turn in a written summary of your article and any slides that you may have used for your presentation. What should go in the report? The same material that you included in your presentation! Essentially, you are writing down what you said aloud during your presentation. I envision these being 3-5 pages in length. Given that your summaries were one page, you should not have too much trouble reaching three pages after adding background to the topic being studied, details about the methods, explanations about the statistics (equations, figures, examples, etc.) utilized, and any conclusions that can be drawn from these results.

\begin{tabular}{|l|}
\hline Group Members \\
\hline$[$ List names here] \\
\hline \\
\hline \\
\hline \\
\hline \\
\hline \\
\hline
\end{tabular}

Please contact your partners and start looking for a paper! I can help point you in the right direction if you are having trouble and be sure to ask me if you aren't sure if the paper that you have picked out is appropriate for this project. Also, the papers I posted on Moodle as examples are available for you to use, first come, first serve! [But with so many topics to pick from, why settle?]

\section{Project Presentations and Written Report Scoring Guide}

Goal: To be able to write and speak in the language of statistics.

In order to accomplish this goal, I would like each group to:

1) Find a journal article of interest to the members of your group

2) Present your article to the class by describing:

a. The motivation for the project

b. The data collection and processing methods

c. The statistical methods that were used to analyze the data

d. The results and conclusions drawn by the authors

3) Submit a 3-5 page written report about your article. Your written report should mirror your presentation.

\section{Names}

The presentation and paper were graded using the same set of criteria and each section is worth the same number of points for both parts of the project. For each Section, a '0' is assigned only if no attempt was made to address this part of the study. Further points are awarded based on the information provided to answer each of the questions within each section. Points earned are listed as Presentation Score | Paper Score. Add down these columns to get the total score for each part of the project. The presentation and paper are both worth 40 points, while the project proposal and group meeting/participation are both worth 10 points, for a total of 100 points.

\section{Presentation | Paper Score}

\section{Introduction [6]}

Total:

- Motivation for project - Why is it important to study this topic?

- How do the authors plan to study this topic?

- Are there broader consequences or implications?

\section{Data Collection / Experimental Design [8]}

Total:

- How many subjects were involved in the study?

- What were the different treatment groups? How many in each group?

- Were there any problems with the data collection?

- $\quad$ Did people drop out of the study?

\section{Statistics [16]}

Total:

- What was the main method used for statistical analysis?

- If this is a method that we have covered in class:

- Explanation to the class of how this method can be used.

- Equations used to obtain results

- What are the values for each variable in the equations?

○ Number of degrees of freedom?

- If this is not a method that we have covered in class:

○ How does this method work?

- Can you give a simple and clear explanation?

o What assumptions do you have to make to use this method?

- What kind of results does it give?

○ How do you interpret the results?

- $\quad$ Either way, use some of their data to walk through the process at least once

\section{Results / Conclusions [10]}

Total:

- Share the main results of the study 
- You can skip the details of the statistics after you have shown the method once

- Are the results statistically significant? What are the p-values?

- What conclusions about the data can you draw?

- Are there any broader conclusions or implications from this study?

\section{Presentation | Written Report Total [40 each]}

Total:

Proposal + Participation Total [10 each]

Total:

Overall Project Grade [100]

Total:

\section{Example of Student Feedback Form:}

Group \#1: --Names --

1) What is one thing that you liked about this presentation? [Ex. Interesting topic, clear visual aid, good explanation of some idea, etc.]

2) What is one thing that could have been improved in this presentation? [Ex. More background on some part of the study, unclear explanation of some idea, general comments on public speaking, etc.]

Group \#2: --Names --

1) What is one thing that you liked about this presentation? [Ex. Interesting topic, clear visual aid, good explanation of some idea, etc.]

2) What is one thing that could have been improved in this presentation? [Ex. More background on some part of the study, unclear explanation of some idea, general comments on public speaking, etc.]

Group \#3: --Names --

1) What is one thing that you liked about this presentation? [Ex. Interesting topic, clear visual aid, good explanation of some idea, etc.]

2) What is one thing that could have been improved in this presentation? [Ex. More background on some part of the study, unclear explanation of some idea, general comments on public speaking, etc.]

\section{REFERENCES}

[1] L.J. Carnell. The Effect of a Student-Designed Data Collection Project on Attitudes Towards Statistics, Journal of Statistics Education, Vol. 16, No. 1, 2008. Online available at http://www.amstat.org/publications/jse/v16n1/c arnell.html

[2] R.E. Kirk. (2002), Teaching Introductory Statistics: Some Things I Have Learned, paper presented at the Annual
Conference of the American Psychological Association, Chicago, IL (ERIC Document Reproduction Service No. ED 473 611), 2002.

[3] United States Census Bureau. 2010 Census, Online available at http://www.census.gov.

[4] Gallup New Organization. Online available at http://www.gallup.com/home.aspx.

[5] Association of American Medical Colleges. MCAT2015 Frequently Asked Questions, Online available from: https://students-residents.aamc.org/advisors/faq/faqs-for-ad visors-about-new-mcat-exam/.

[6] L. Dierker, E. Kaparakis, J. Rose, A. Selya, and D. Beveridge. Strength in Numbers: A Multidisciplinary Project-based Course in Introductory Statistics, The Journal of Effective Teaching, Vol. 12, No. 2, 4-14, 2012.

[7] M. Forster and H. MacGillivray. Student Discovery Projects in Data Analysis, in C. Reading (Ed.), Data and context in statistics education: Towards an evidence-based society, Proceedings of the Eighth International Conference on Teaching Statistics (ICOTS8, July, 2010), Ljubljana, Slovenia, 2010.

[8] B. Chance. Integrating pedagogies to teach statistics, in J. Garfield (Ed.), Innovations in Teaching Statistics, MAA Notes \#65, Mathematical Association of America, Washington, 2005.

[9] GAISE College Report 2016. Guidelines for Assessment and Instruction in Statistical Education (GAISE) College Report, The American Statistical Association. Online available at http://www.amstat.org/education/gaise.

[10] J.E. Anderson and E.A. Sungur. Community Service Statistics Projects, The American Statistician, Vol. 53, No. 2, 132-136, 1999.

[11] R. Snee. What's Missing in Statistical Education, American Statistician, Vol. 47, No. 2, 149-154, 1993.

[12] S.L. Weinberg and S.K. Abramowitz. Making General Principles Come Alive in the Classroom Using an Active Case Studies Approach, Journal of Statistics Education, Vol. 8 , No. 2, 2000. Online available at http://www.amstat.org/publications/jse/secure/v8n2/weinbe rg.cfm

[13] S. Fillerbrown. Using Projects in an Elementary Statistics Course for Non-Science Majors, Journal of Statistics Education, Vol. 2, No. 2, 1994. Online available at http://www.amstat.org/publications/jse/v2n2/fillebrown.ht $\mathrm{ml}$

[14] G. Smith. Learning Statistics By Doing Statistics, Journal of Statistics Education, Vol. 6, No. 3, 1998. Online available at http://www.amstat.org/publications/jse/v6n3/smith.html

[15] J. Garfield. An Authentic Assessment of Students' Statistical Knowledge, in National Council of Teachers of Mathematics 1993 Yearbook: Assessment in the Mathematics Classroom, ed. N. Webb, Reston, VA: NCTM, pp. 187-196, 1993.

[16] J. Garfield. How Students Learn Statistics, International Statistical Review, Vol. 63, No. 1, 25-34, 1995.

[17] J. Garfield. Teaching Statistics Using Small-Group 
Cooperative Learning, Journal of Statistics Education, Vol. 1, No. 1, 1993. Online available at

http://www.amstat.org/publications/jse/v1n1/garfield.html

[18] B. Chance. Experiences with Authentic Assessment Techniques in an Introductory Statistics Course, Journal of Statistics Education, Vol. 5, No. 3, 1997. Online available at http://www.amstat.org/publications/jse/v5n3/chance.html

[19] N. Radke-Sharpe. Writing as a Component of Statistics Education, The American Statistician, Vol. 45, No. 4, 292-293, 1991.

[20] J. Ledolter. Projects in Introductory Statistics Courses, The American Statistician, Vol. 49, No. 4, 364-367, 1995.

[21] G. Samsa and E.Z. Oddone. Integrating Scientific Writing into a Statistics Curriculum: A Course in Statistically Based Scientific Writing, The American Statistician, Vol. 48, No. 2, 117-119, 1994.

[22] A.J. Stromberg and S. Ramanathan. Easy Implementation of Writing an Introductory Statistics Courses, The American Statistician, Vol. 50, No. 2, 159-163, 1996.

[23] National Center for Biotechnology Information. PubMed.gov, US National Library of Medicine, National Institute of Health. Online available at http://www.ncbi.nlm.nih.gov/pubmed/.

[24] Google Scholar. Online available at http://scholar.google.com/.

[25] C. Lago-Peñas, J. Lago-Ballesteros, A. Dellal, and M. Gỏmez. Game-related statistics that discriminated winning, drawing, and losing teams from the Spanish soccer league, Journal of Sports Science and Medicine, Vol. 9, 288-293, 2010.

[26] T.K. Aldrich, J. Gustave, C.B. Hall, W.H. Cohen, M.P. Webber, R. Zeig-Owens, K. Cosenza, V. Christodoulou, L. Glass, F. Al-Othman, M.D. Weiden, K.J. Kelly, and D.J. Prezant. Lung Function in Rescue Workers at the World Trade Center after 7 Years, The New England Journal of Medicine, Vol. 362, No. 14, 1263-1272, 2010.

[27] P.T. Bradshaw, S.K. Sagiv, G.C. Kabat, J.A. Satia, J.A. Britton, S.L. Teitelbaum, A.I. Neugut, and M.D. Gammon. Consumption of sweet foods and breast cancer risk: a case-control study of women on Long Island, New York, Cancer Causes Control, Vol. 20, 1509-1515, 2009.

[28] E.J. Lyons, D.F. Tate, D.S. Ward, K.M. Ribisl, J.M. Bowling, and S. Kalyanaraman. Do Motion Controllers Make Action Video Games Less Sedentary? A Randomized Experiment, Journal of Obesity, Article ID 852147: 7 pages, 2012. doi: $10.1155 / 2012 / 852147$

[29] D. Shmueli, J.J. Prochaska, and S.A. Glantz. Effect of Smoking Scenes in Films on Immediate Smoking: A Randomized Controlled Study, American Journal of Preventative Medicine, Vol. 38, No. 4, 351-358, 2010. doi: 10.1016/j.amepre.2009.12.025.

[30] E.A. Winkler, J.K. Yue, J.F. Burke, A.K. Chan, S.S. Dhall, M.S. Berger, G.T. Manley, and P.E. Tarapore. Adult sports-related traumatic brain injury in United States trauma centers, Neurosurgical Focus, Vol. 40, No. 4, E4, 2016.

[31] A.G. Small, L.M. Thwe, J.A. Byrne, L. Lau, A. Chan, MAppStat, M.E. Craig, C.T. Cowell, and S.P. Garnett.
Neuroblastoma, Body Mass Index, and Survival: A Retrospective Analysis, Medicine, Vol. 94, No. 14, 2015. DOI: 10.1097/MD.0000000000000713

[32] J.A. Schmidt, S. Rinaldi, P. Ferrari, M. Carayol, D. Achaintre, A. Scalbert, A.J. Cross, M.J. Gunter, G.F. Fensom, P.N. Appleby, T.J. Key, and R.C. Travis. Metabolic profiles of male meat eaters, fish eaters, vegetarians, and vegans from the EPIC-Oxford cohort, American Journal of Clinical Nutrition, Vol. 102, 1518-1526, 2015.

[33] A.S. Douds, D. Howard, D. Hummer, and S.L. Gabbidon. Public opinion on the affluenza defense, race, and sentencing decisions: results from a statewide poll, Journal of Crime and Justice, Vol. 39, No. 1, 230-242, 2016.

[34] M.M. Triola and M.F. Triola. Biostatistics for the Biological and Health Sciences, $2^{\text {nd }}$ Edition, Pearson, Boston, 2017.

[35] R. Peck, C. Olsen, and J.L. Devore, J.L. Introduction to Statistics and Data Analysis, $5^{\text {th }}$ Edition, Brooks/Cole, Boston, 2015.

[36] Wikipedia, the Free Encyclopedia. Online available at http://en.wikipedia.org.

[37] M.M. Ojeda, H. Sahai, and A. Khurshid. Disseminating Significant Learning in Statistics Service Courses, Science Journal of Mathematics and Statistics, Article ID: sjms-103, 9 pages, 2012. doi: 10.7237/sjms/103

[38] J.P. Holcomb and R.L. Ruffer. Using a Term-Long Project Sequence in Introductory Statistics, The American Statistician, Vol. 54, No. 1, 49-53, 2000. 